\title{
Syntactical Error on Students' Descriptive Composition
}

\author{
Ignatius Javier C. Tuerah, Jeane Tuilan, Sandra Rakian
}

\begin{abstract}
This study tries to identify types and causes of errors committed by students of English department at Language and Arts Faculty in their compositions. The compositions were descriptive in nature written by twenty-two fifthsemester students based on a predetermined topic. The data obtained was identified and then categorized to determine the types of and causes of errors. The data analysis indicated that there were ten types committed by the subjects. These ten types of errors are due to four potential causes of errors: intralingual transfer, insufficient learning/teaching, incomplete application of target language rules, and the nature of the target language system/rules.
\end{abstract}

Key words: errors, intralingual transfer

\section{INTRODUCTION}

The purpose of this research is to describe and to deeply examine all syntactical errors on descriptive composition of the English students. By forming this research, it is so much expected to prevent all kind of errors in descriptive composition.

The ability to write effectively is becoming increasingly important in our global world. As advances in transportation and technology allow people from nations and cultures throughout the world to interact with each other, communication across languages become even more important. As a result, the ability to write (and to speak) a second or 
foreign language is becoming widely recognized as an important skill for education, business, and personal reasons. The reason is the ability to write well has a very close relationship to academic and professional success. Grabowski (1996) noted that mastery of this skill is an important prerequisite of cultural and education participation. Therefore, a good command of this skill is undeniable for every student in schools strives to achieve.

Writing is not a naturally acquired skill. It is usually learned or culturally transmitted as a set of practices in formal instructional settings. It involves the ability to either tell or retell pieces of information in narration, description or to transform information into new texts, as in expository or argumentative writing. As a continuum of activities, it ranges from the more mechanical or formal aspects of writing down on the one end, to more complex act of composing on the other end (Omaggio, 1993).

To write well in English, students are required to have good linguistic knowledge and cultural knowledge of the target language community. They should have sufficient stock of vocabulary; they should know how words are formed; how words are arranged to make grammatical sentences; and how sentences are arranged to compose coherent texts. In addition to this, they should also have sufficient knowledge of communicative conventions in the language. This will allow them to construct meanings in ways that are appropriate within the target 
language community. That is why writing is considered, by many, as a difficult skill to acquire.

Writing good compositions in English is not an easy thing for foreign language learners to do. Although other factors may inhibit students' ability in writing, the following factors are seen as the most dominant ones. First, they are human, none of them are perfect; second, they are learners who still do not have the necessary linguistic ability; Kern (2000) noted that limited knowledge of vocabulary, language structure, and content hinder a L2 writer' performance. Third, they are sometimes, if not often, influenced by their mother tongue. They transfer what they have in their mother tongue into the target language; fourth, insufficient learning and/or teaching may also be a potential source of the problem. Last but not least, the system of target language itself is difficult for them.

Experts and researchers have identified sources of errors committed by second or foreign language learners. Selinker (1972) noted that errors in language learning resulted from (a) mother tongue transfer, (b) transfer of training, (c) strategies of second language learning, (d) strategy transfer of training, and (e) overgeneralization of target language linguistic material. Richards (1973) states that sources of errors are (a) overgeneralization, (b) ignorance of rule restriction, (c) incomplete application of rules, and (d) false concepts. Corder (1973) points out that errors committed by second/foreign language learners were caused by (a) interlingual transfer, (b) overgeneralization of target language rules, and 
(c), insufficient teaching. To sum up, errors in second or foreign language are caused by (a) intralingual transfer, (b) interlingual transfer, and (c) insufficient learning/teaching.

Lots of studies dealing specially with identification of errors in foreign language learning in general, particularly in writing have been done so far. Abi Samra (2003), for example, found that $35 \%$ of errors in writing were caused by transfer/interlingual interference, and developmental/ intralingtual $64.1 \%$. Work on over-generalization errors is reported by Richards (1974, pp. 174-188). Farooq (1998) focused on both transfer and overgeneralization errors. All these studies focused on transfer and/or overgeneralization errors made EFL students.

All experts' opinions and findings of the above-mentioned studies are valuable input for English teachers and students learning English as a second or foreign language. In connection with this, Selinker (1969), for example, points out that errors are significant in three respects: (1) errors are important for the language teacher because they indicate the learner's progress in language learning; (2) errors are also important for the language researcher as they provide insights into how language is learnt; and (3) finally, errors are significant to the language learner himself/herself as he/she gets involved in hypothesis testing. In other words, errors are mirrors by means of which teachers and students see if things need improvement in their teaching and learning a second/foreign language. 
Lots of studies have dealt with errors committed by students in their English compositions. However, it should well-remembered that one of the common difficulties in understanding the linguistic system of foreign language learners is the fact that such system cannot be directly observed. It must be inferred by means of analyzing learners' production and comprehension data. Therefore, more studies need be done in order to obtain more information about the nature of errors in second/foreign language.

\section{RESEARCH METHODS}

The studies which tried to identify and describe types of syntactical errors made by the fifth-semester students at the English department of Manado state University was a descriptive and qualitative in nature seen in terms of the data and data analysis. The data was collected from 20 fifthsemester students using a writing test in which each of them was to write a composition based on the topic My visit to Bunaken island. The composition should be descriptive in nature and consisted of introductory, developmental and concluding paragraphs written in 90 minutes. In collecting the data the researcher was used the procedure put forward by Lichtman (2006). Thus, the data obtained were identified, categorized, and analyzed to determine the types of errors committed by the subjects in their writings. The findings later on are discussed and explained in terms of the factors affecting the occurrence of errors in writings. 


\section{Findings and discussion}

The data obtained in this study were collected using writing test in which each of the subjects wrote a composition based on the topic given. The data obtained from the test were analyzed according to the types of errors, and the subjects committed each type of errors.

The total numbers of errors made by twenty two students were 191 . After analyzing the errors it indicates that tenses/verb-forms was the highest frequency with a total of 58 errors, and successively followed by derivation (46), singular/plural (20), parallelism (20), word order (16), subject-verb agreement (14), prepositions (9), conjunctions (4), word omission (3), and pronouns (1). This finding indicates that errors in tenses and derivation which occurred in high frequency posed problem to majority of the students in this research. Other types of errors, such as singular/plural, parallelism, word order, subject-verb agreement, and prepositions should get more attention from the English teachers or writing instructors and from the students. The rest, conjunctions, word omission, and pronoun, are less crucial seen in terms of the number of errors committed.

\section{Frequency of Subjects}

Of this total number of errors, tenses contribute the most number of errors, a total of 58 committed by 21 subjects. Error related to derivation is 
second highest with 46 errors made by 20 subjects. Incorrect use of plural forms is the third in position with a total of 20 errors made by 13 subjects; parallelism is the fourth with the same number of errors as plural forms, but made by 12 subjects; subject-verb agreement is the fifth with a total of 14 errors made by 11 subjects; the sixth is word order with a total of 16 errors made by 9 subjects. Only smaller number of subjects made error when using prepositions, conjunctions, word omission and pronouns.

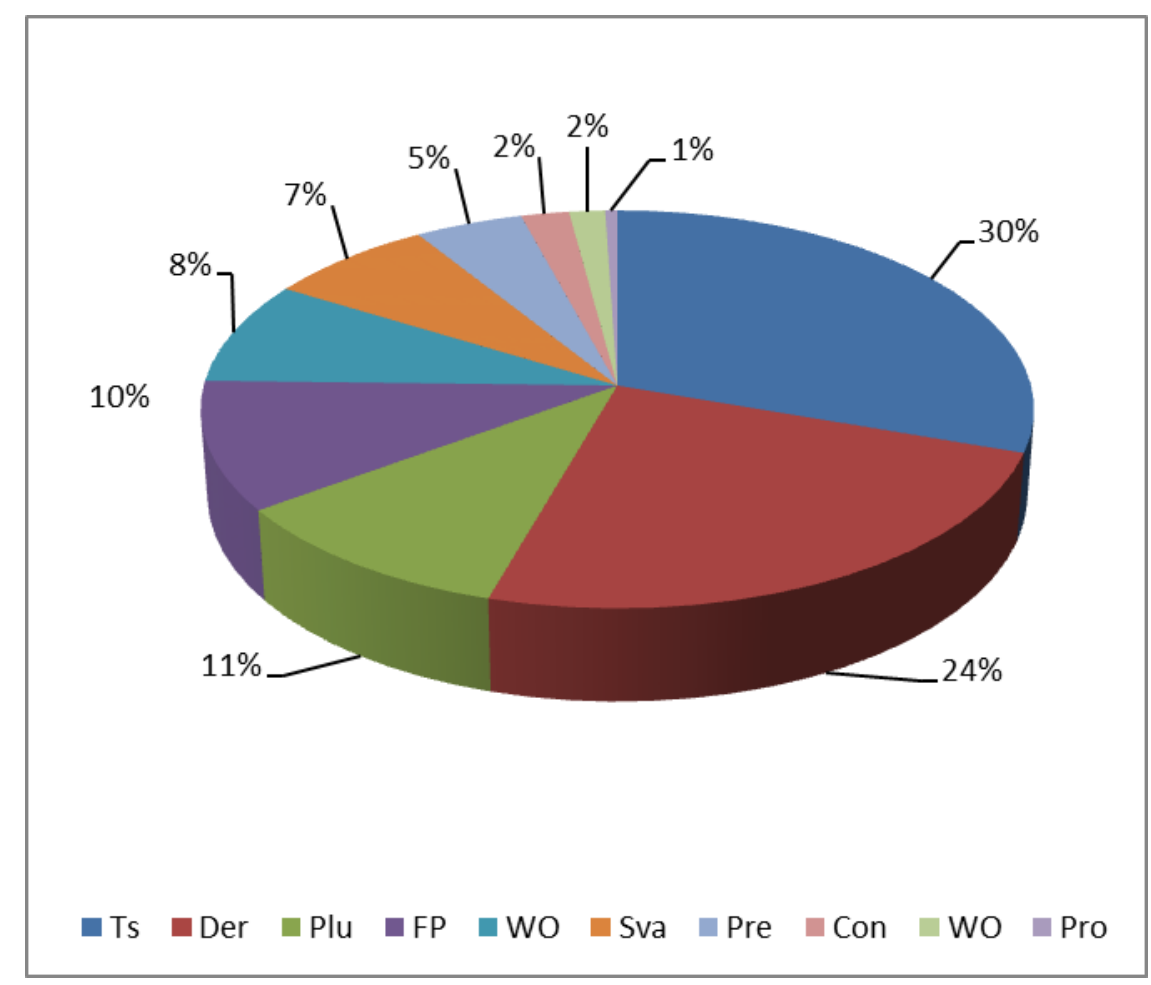

Figure 1. Types of Error in Percentage

Legend:
Ts $=$ tense
Der = derivation
$\mathrm{PI} \quad=$ singlar/plural
$\mathrm{FP} \quad=$ faulty parallelism
$\mathrm{WO}=$ word order
$\mathrm{SVa}=$ subject-verb agreement 
$\begin{array}{ll}\text { Prep }=\text { preposition } & \text { Con }=\text { conjunction } \\ W M=\text { word omission } & \text { Pron }=\text { pronouns }\end{array}$

\section{Causes of Errors}

Sources or causes of errors in language learning can be traced back in data taken from the subjects' writings. In (1a), for example, furnitures was pluralized by adding a plural marker, $s$. The clauses why did she visit the island (1b), why did you move to another hotel, (1c), and where is the best restaurant here (1d) in those noun, adjective, and adverb clauses respectively. Although begin with wh-words, they are not whquestion, but statements. In these four examples, the subjects apply the rule of plural formation and wh-pattern in contexts similar to what they have already learned or known before. Such an error is known as intralingual transfer.

(1a) The furnitures in the hotel was very expensive.

(1b) I asked an American tourist why did she visit the island.

(1c) Give me the reason why did you move to another cottage

(1d) I don't know where is the best restaurant here.

Intralingual transfer is not the only cause of errors in language learning. In constructing passive sentences, as in (2a) and (2b), the subjects wrongly used the verb forms. The verbs were incomplete due to the omission of the be-form. The correct use of the participles is an indication that the subjects knew how to construct how to construct passive sentences. Furthermore, in (2c) and (2d), a number of and lots of 
were followed by singular countable nouns, friend in (2c), hotel and cottage in $(2 \mathrm{~d})$.

(2a) Sea food served_by all the restaurants in the island.

(2b) The cultural celebration held once a year in the island.

(2c) There I meet a number of friend of mine.

(2d) There are lots of hotel and cottage in the island.

(2e) The weather was much good than it was the day before Similar with (2a) and (2b), deviations from the target language rules can be seen in (2c) and (2d). In these examples, the plural marker was not added to the countable nouns which come after a number of and lots of. As in the other examples, in (2e), errors committed resulted from incomplete application of target language rules.

Deviations from target language rules are also caused by other factors. Some language areas, prepositions and conjunctions are among others, have been repeatedly introduced to subjects since they were in first grade of junior high school. However, still they found it difficult to use them properly. Implicitly, the two examples indicate that the subjects of this study did not know exactly when to use preposition indication position and direction such as in, on, at, among, between, to and for as in these fexamples.

(3a) We went to Bunaken in Sunday.

(3b) In the boat I was sitting among my father and mother.

(3c) We all got in board soon after we arrived at the harbor, 
(3d) The boat ran more faster than it was expected.

(3e) The weather was much good than it was the day before.

(3f) The American tourist will complete his tour in Indonesia next month on the $26^{\text {th }}$.

In (3a) and (b), more faster than ... in (3c) and much good than ... in (3d) used their writings are a minor indicator that the subjects have once learned the degree of comparisons in English. Similarly, in (3e), Adverb of time should be place at the beginning or at the end of a sentence is placed after next month. In English, it is common to put an adverb of time at the end, but sometimes at the beginning of sentences. If more than one adverb of times successively follows one another in a sentence (3f), the rule is the smallest unit the first, the largest the last. All the abovementioned examples in implicitly reveal that the subjects have insufficient knowledge of the target language rules. This insufficient knowledge may be due to insufficient learning or teaching.

It has been pointed out before that errors caused by incorrect use of tenses rank the highest with a total of 58 errors committed by 22 subjects. It means that made errors in using tenses. The errors due to incorrect of tenses are dominated by perfect tenses. It seems that they still find it difficult to make a distinction, for example, past tense and present perfect tense.

Derivation, which is roughly defined as words having different class or grammatical functions as the words from which they are derived or 
formed, ranks the second highest seen in terms of the total number of errors and subjects committing the errors. Almost the same as tenses, incorrect use of derivations was made by 20 with a total of 46 errors. The following examples show how errors in using derivations were committed.

(4a) Actually the beaches in Manadotua are more beautifully than those in Bunaken.

(4b) Playing on the beach is really fascinated.

(4c) All the fruit sold in the beach was spoiled.

(4c) The sun was shining bright.

A close look at errors related to tenses, derivations, and parallelism leads to the conclusion that intralingual transfer, insufficient learning/teaching, incomplete application of target language rules are not the only reasons for committing errors. Concept of tense or verbs change with time which is confusing and rules governing word formation which are complex are examples which lead to the conclusion that the nature of target language system contributes to error committing.

In brief, this study reveals that errors committed by the subjects were due to incorrect use of tenses, derivation, singular/plural, parallelism, word-order, subject-verb agreement, preposition, conjunctions, word omission, and pronouns. These errors occurred at phrasal, clausal, and sentential levels. Incorrect use of tenses and derivation rank the highest in frequency of errors. Errors in areas such as singular/plural, parallelism, word order, and subject-verb agreement were committed by more than 
half of the subjects. Majority of the subjects found correctly used prepositions, conjunction and pronouns in their writings. Thus, errors committed by the subjects occur at phrasal, clausal, and sentential levels.

Four sources or causes of errors are identified in this study. They are (1) intralingual transfer, (2) insufficient learning/teaching, (3) incomplete application of target language rules, and (4) the nature of target language system. This finding indicates that mother tongue interference is not the dominant factor in for error committing. It means that to minimize error committing, factors related to the target language system and language learning/teaching should be paid attention to, because they are potential sources of errors.

Types and sources of errors identified in this study are not an end in themselves but a means to an end. In context of writing, they are a means of feedback for teachers reflecting how effective they are in their teaching style and what changes they have to make to get higher writing performance from their students. Errors also give syllabus designers valuable data which can be used as the basis to decide on what to teach to what level and age group.

\section{Conclusion}

Ten types of errors identified in this study are caused by intralingual transfer, insufficient learning/teaching, incomplete application of target language rules, and the nature of the target language system or rules. The errors identified are not only a valuable input for teachers and syllabus 
designers, but also an indication that errors in language learning cannot be avoided. Basically, error committing is human nature indicating that we are normal human beings.

Considering the facts found in doing the research, it is hoped for all teachers and syllabus designers to do more active and creative in teaching and learning processes.

\section{REFERENCES}

AbiSamra, Nada. An Analysis of Errors in Arabic Speakers' English Writings. Second Language Acquisition, English 345, January 2003.

Farooq, M. U. (1998). Contrastive and error analysis based teaching strategies. Aichi Women's Junior College- Retrieved December 30, 2003 from

http://www.cels.bham.ac.uk/resources/essays/farooq2.pdf

Grabowski, J. Writing and Speaking: Common Grounds and Differences to ward a Regulation Theory of Written Prtoduction. In C. M. Levy and S. Ransdell (eds), The Science of Writing. NJ: Lawrence Earbaum Associates. 1996.

Jain. M. P. Error Analysis: Source, Cause, and Significance. In Richard, J. C. (ed)). Error Analysis, Perspective on Second Language Acquisition. London: Longman, 1974

Lichtman, Marilyn. Qualitative Research in Education: A User's Guide. London: Sage Publication, Inc. 2006.

Omaggio Hadley, A. Teaching language in context. Boston: Heinle and \& Heinle. 1993

Richard, J. C. A-non-Contrastive Approach to Error Analysis. In Richards J. C. (ed) Error Analysis, Perspective on Second Language Acquisition. London: Longman, 1974. 
Selinker, L. 1969. Interlanguage. International Review of Applied Linguistics, 3, 114-132.

1972. Interlanguage. International Review of Applied Linguistics, 10, 209-231. 